1990 exp

DOE/EIA-8558-2

Vol. 2 of 6

Order No. 522/2

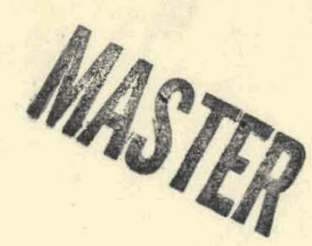

\title{
The Integrating Model of the Project Independence Evaluation System. Volume ll-Primer
}

March 1979

Prepared for:

U.S. Department of Energy

Energy Information Administration

Assistant Administrator for Applied Analysis

Under Contract No. EC-77C-01-8558 


\section{DISCLAIMER}

This report was prepared as an account of work sponsored by an agency of the United States Government. Neither the United States Government nor any agency Thereof, nor any of their employees, makes any warranty, express or implied, or assumes any legal liability or responsibility for the accuracy, completeness, or usefulness of any information, apparatus, product, or process disclosed, or represents that its use would not infringe privately owned rights. Reference herein to any specific commercial product, process, or service by trade name, trademark, manufacturer, or otherwise does not necessarily constitute or imply its endorsement, recommendation, or favoring by the United States Government or any agency thereof. The views and opinions of authors expressed herein do not necessarily state or reflect those of the United States Government or any agency thereof. 


\section{DISCLAIMER}

Portions of this document may be illegible in electronic image products. Images are produced from the best available original document. 


\section{Available from:}

National Technical Information Service (NTIS) U.S. Department of Commerce

5285 Port Royal Road

Springfield, VA 22161

Price:

Printed Copy: $\$ 4.50$

Microfiche: $\quad \$ 3.00$ 
DOE/EIA-8558-2

Vol. 2 of 6

UC Dist. 13

\section{The Integrating Model of the Project Independence Evaluation System. Volume II: Trimer}

March 1979

Prepared by:

Michael L. Shaw, Mary J. Hutzler

Logistics Management Institute

Washington, D.C. 20016

Under Contract No. EC-77C-01-8558

Prepared for:

U.S. Department of Energy

Energy Information Administration

Assistant Administrator for Applied Analysis Office of Integrative Analysis

Mid-Term Analysis Division

Washington, D.C. 20461 
This report was prepared under Department of Energy (DOE) Contract Number EC-77C-01-8558 and does not necessarily state or reflect the views, opinions, or policies of the DOE or the Federal Government. References to trade names or specific commercial products, commodities, or services in this report do not represent or constitute an endorsement, recommendation, or favoring by DOE of the specific commercial product, commodity, or service.

Released for printing: October 3, 1979 
This contractor report was prepared by Logistics Management Institute and provides documentation of the version of the Project Independence Evaluation System (PIES) as it existed on January 1, 1978. Since that date, PIES has evolved into what is now called the lid Range Energy Market lodel (MEMM), a major component of the Mid Range Energy Forecasting system (MEFS). Major structural changes that have occurred between January 1, 1978 and January 1, 1979, are documented in the supplemental volume entitled, "Revisions to the Midterm Energy Market Model Relating to Natural Gas Regulation, Advanced Technologies, Coal Demand and Dynamics." Together, the six volume set of documentation, plus the supplemental volume on revisions, form the most comprehensive and up-todate version of MEMM documcntation currently available, documentation which significantly surpasses in both form and content the single volume published in January, 1977.

Although this documentation has not gone through the appropriate review process and clearance procedures to be published as an EIA endorsed report, it is currently being made available in its present form as an interim measure to satisfy many outstanding requests for MEMM documentation. As this report has not been submitted to comprehensive review, EIA does not endorse any information contained herein. The documentation is presently being subjected to comprehensive review both inside and outside the Department of Energy. A contract is currently in process to update it to the version used for the 1978 Annual Report to Congress (published in July 1979). This new version of the documentation report is intended to bring the MEMM documentation into conformity with EIA's documentation standards and to respond to any issues raised as a result of the review process. The results of the latter effort will result in a set of MEMM documentation fully cleared and endorsed by EIA, available in 1980. 
This documentation describes the Project Independence Evaluation System (PIES) Integrating Model as it existed on January 1, 1978. The complete documentation consists of six volumes describing the various aspects of the Integrating Model as follows:

- Volume $I$ is an executive summary, providing a simple, nontechnical overview of PIES.

- Volume II is a primer, describing and illustrating the basic inputs to the PIES algorithm.

- Volume III is a user's guice, describing scenario specification and the opcrational procedures for running the Integrating Model.

- Volume IV is the main model documentation, describing the theoretical basis of the Integrating Model and each of the supply submodels.

- Volume $\mathrm{V}$ is code documentation, describing the data processing aspects of PIES: the data flow through the PIES programs, the functions performed by each program, the data inputs and outputs, and the PIES naming conventions.

- Volume VI is data documentation, containing the standard table data used for the April 1978 Administrator's Annual Report, along with primary data sources and the office responsible. It also contains a copy of a PIES Integrating Model Report with a description of its contents.

The data and scenarios used in these volumes are those used in the 1972 EIA Annual Report to Congress, prepared by the Energy Information Administration. In all volumes, we refer to this report as the Administrator's Annual Report (AAR). 


\section{TABLE OF CONTENTS}

\section{Page}

Preface ..................... i i

List of Figures and Tables................ ' iv

\section{Section}

I. INTRODUCTION ................ I 1

Purpose .................... I- 1 Types of Energy Models ................ I- 1

II. PIES METHODOLOGY ................ II- 1 Introduction . . . . . . . . . . . . . . . . . II- 1 PIES Components ................ II- 1 The Supply Representation ............ II- 2 The Demand Representation ... . . . . . . . . . II- 6 Integration of Supply and Demand . . . . . . . . . II- 8

III. SAMPLE PIES LP PROBLEM ............. III- 1 Market Equilibrium without Constraints. . . . . . . . III- 1 
1. Example Linear Programming Network. . . . . . . . . . . . . II- 3

2. Consumers' and Producers' Surplus. . . . . . . . . . . . . . . Il- 6

3. Approximation of the Demand Curve . . . . . . . . . . . . II- 9

4. Approximation of Supply and Demand Curves . . . . . . . . . . . . . II-11

5. Sample Energy System Network. . . . . . . . . . . . . . . III- 2

\section{LIST ÖF TABLES}

1. Production Levels and Resource Requirements for Coal . . . . . . . III- 1

2. Coal Transport Costs . . . . . . . . . . . . . . . . III- 3

3. Production Levels and Resource Requirements for Oil . . . . . . . . . III- 3

4. Oil Transport Costs to Refinery Centers . . . . . . . . . .. . . . . III- 4

5. Refinery Yields and Costs . . . . . . . . . . . . . . . . . III- 4

6. Oil Transport Costs to Demand Regions . . . . . . . . . . . . . . III- 4

7. Elasticities . . . . . . . . . . . . . . . . . . III- 8

8. Equilibrium Energy Balances . . . . . . . . . . . . . . . III-11

9. Price and Quantity Summary (without constraints) . . . . . . . . . . . III-12 


\section{INTRODUCTION}

\section{PURPOSE}

This is one of a series of six volumes documenting the Project Independence Evaluation System (PIES) Integrating Model. This volume is intended for those with analytical backgrounds who are unfamiliar with PIES. The basic concepts of the PIES algorithm are described, and examples are included which discuss the formulation of hypothetical energy systems in the PIES context. An overview of PIES is contained in Volume I of this documentation series; the computer implementation is contained in Volume V.

TYPES OF ENERGY MODELS

Planners and decision-makers in Government and business increasingly are recognizing the need for energy forecasting. More and more, planning decisions are being linked to energy-related predictions, i.e., to the availability, nature, and price of energy. A number of computer models have been, or are being, developed to support energy forecasting. These models have been developed in research and academic institutions and commercial organizations, and a variety of modeling approaches intended to satisfy differing needs and objectives has resulted.

It is useful to categorize models according to their assumptions and techniques, for example, optimization, simulation, system dynamics, econometric models, equilibrium, etc.

PIES is both an optimization model and an equilibrium model. Energy supply and demand functions are combined in PIES as a linear program where suppliers and consumers optimize their interests. PIES calculates an economic equilibrium within certain tolerance criteria, thus obtaining the quantity and price at which supply equals demand. 
Certain assumptions are inherent in optimization models. For instance, PIES assumes that the market will react in a cost-conscious fashion, that each component will optimize within itself. Certainly, in reality, an individual segment of the economy may not optimize at all, or it may form a coalition with another segment and react in a way optimal to the coalition, but not to individual segments of the economy.

It is important to understand models in terms of their assumptions in order to use them for analysis. However, not only are model assumptions important, but how closely a model deals with the complexity of the real world is also important. For instance, an energy model of the U.S. can be either national or regional in scope. It can model one type of coal or oil, or several different types. Similarly, one type of refinery or utility can be modeled or several types. The transportation network can be only one material/mode combination, or it can contain several different ones and allow transshipment between them.

Thus, model assumptions influence a model's utility for examining different situations. Because more detail increases both computer and analyst costs, there is a cost versus complexity tradeoff.

This primer will aid the reader in understanding what PLES optimizes and how it calculates an energy equilibrium. Further details on this subject are contained in Volume IV, Model Documentation. Through this documentation series, we will see that PIES is a very large and detailed model - more so than any other model of its kind. 


\section{PIES METHODOLOGY}

\section{INTRODUCTION}

PIES is composed of several models, with the goal of determining supply of, and demand for, energy goods in 1985 and 1990. PIES accomplishes this goal by modeling each segment of the nation's energy system to obtain market equilibrium. However, this equilibium is not free of those distortions which arise from Government regulation through taxes, price controls, and other policy actions. Thus, not only must PIES deal with the problem of determining an equilibrium (integrating supply and demand), but it also must deal with how to model policy actions affecting energy equilibria.

This section describes PIES methodology for obtaining an equilibrium. It is a preliminary walk-through of the algorithm, described in more detail in Volume IV of this documentation series. An example of a hypothetical energy system is given in section III. PIES COMPONENTS

PIES calculates the supply of, and demand for, energy through: 1) an integrated supply component, which models the production of oil, natural gas, coal, nuclear fuel, and other energy products; conversion processes, electric utilities and refineries, and transportation between supply, conversion, and demand regions; 2) a demand component, which forecasts the demand for energy and associated prices and elasticities of demand; and 3) a component called the equilibrating mechanism, which integrates the first two components. The actual integration of supply and demand occurs within an equilibrating mechanism, which combines supply and demand functions into a linear program which it then solves recursively, iterating until an equilibrium of supply and demand is obtained.

Several computer programs comprise the supply and demand components. The programs dealing with production, conversion and transportation activities produce the 
integrated supply network. Essentially, the integrated supply network is the LP representation of the supply of energy goods from production to demand centers. Thus, it must include conversion and transportation activities in order to represent a total supply cost to the consumer. We will-assume for purposes of discussing the equilibrating mechanism that the integrated supply data are in a proper format for solution by an LP algorithm.

The demand component interfaces directly with the equilibrating mechanism, which accepts forecasts of quantities, prices, and elasticities, and from these computes the demand values necessary for the LP. The remaining discussion will describe the PIES algorithm from the perspective of the equilibrating mechanism, without discussing the derivation of the supply and demand data.

THE SUPPLY REPRESENTATION

To understand how the integrated supply network is modeled, consider the following example. Let the circles in Figure 1 represent the supply of, and demand for, energy materials. For instance, let circles A and B represent the. supply of coal and crude oil, respectively. Let the diamond represent a conversion activity; in this example, the diamond labeled $\mathrm{F}$ is a refinery. Also, assume the squares to be means of transportation between supply, conversion, and demand activities.

What is being modeled in Figure 1 is the conversion of crude oil to, say, residual oil, which is used as a final demand product, and the supply of coal to a refinery for its internal use and as a final demand product. The shipment of primary materials, coul and crude oil, to conversion and demand centers is represented by transportation links.

To model these energy activities mathematically, two different types of equations are used: process limit equations and material balance equations. Process limit equations restrict the capacity of facilities. Material balance equations keep the inputs and outputs of an activity in balance; that is, the material flowing into an activity must equal the 


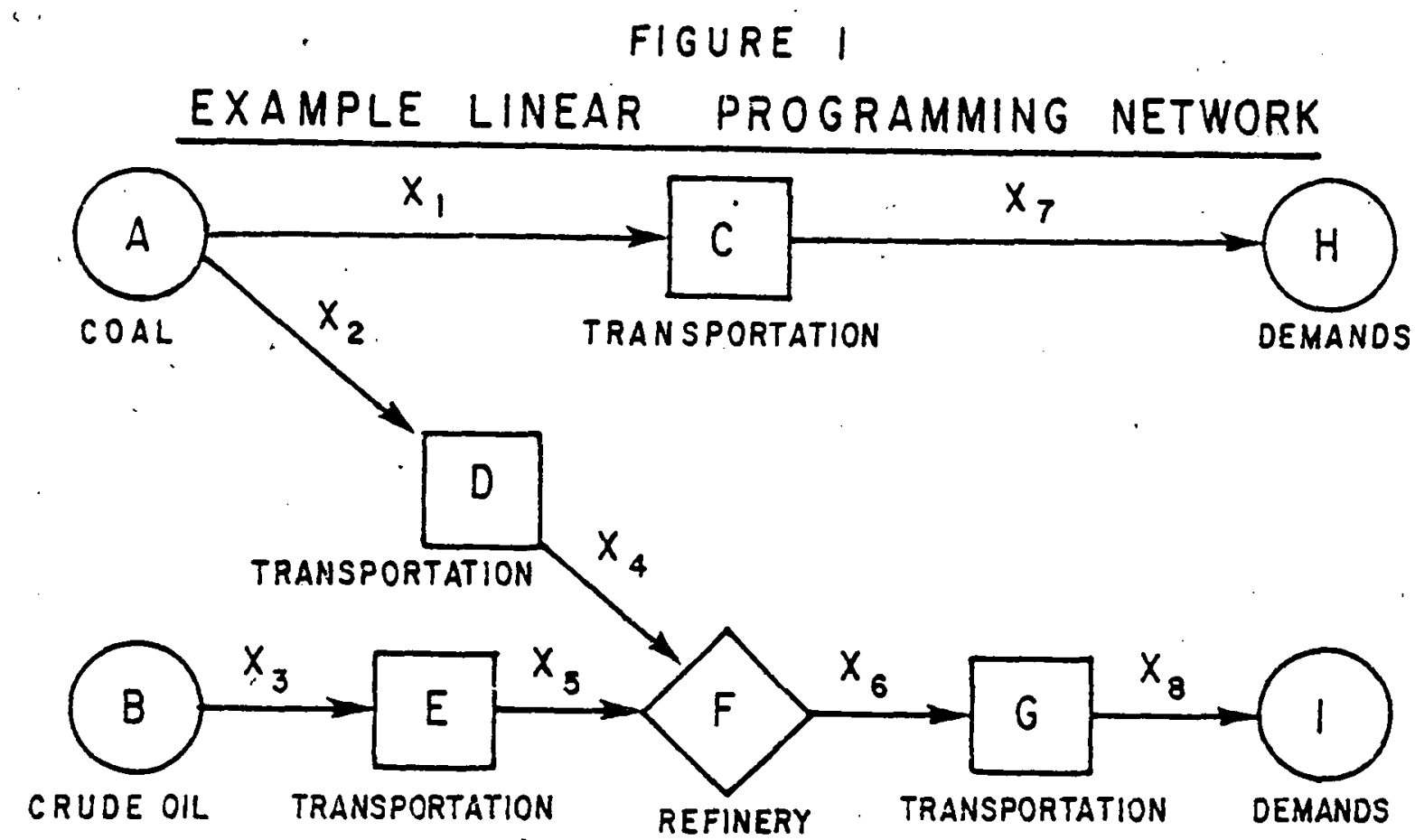

material flowing out of that activity less any losses due to the conversion efficiency of the process. These two types of equations are constraints in the LP problem.

Now, let the $x_{i}, i=1, \ldots, 8$ in Figure 1 represent the quantity of material flowing along the arcs. Assume that $b_{1}$ is the maximum supply of coal in the system and that $b_{2}$ is the maximum supply of crude oil in the system. Then, the first set of constraints, on total supply, is:

$$
\begin{array}{r}
x_{1}+x_{2} \leq b_{1} \\
x_{3} \leq b_{2} .
\end{array}
$$

Referring to Figure 1, $x_{1}$ units of coal are transported to a demand center at circle $\mathrm{H}$. Thus, to preserve material balance, $\mathrm{x}_{1}-\mathrm{x}_{7}$ must equal zero; that is, the quantity of coal obtained from supply source A must equal the quantity of coal demanded at demand point $\mathrm{H}$. Likewise, the coal obiained from source $A$ and transported to the refinery $(F)$ must satisfy the fuel needs of the refinery. Thus, $x_{2}-x_{4}=0$. 
Similarly, the tranportation of crude oil from source $B$ to the refinery must preserve . material balance; thus, $x_{3}-x_{5}=0$. The conversion process at the refinery translates crude oil and coal to residual oil represented by the mathematical equation $\mathrm{x}_{4}+\mathrm{x}_{5}-\mathrm{x}_{6}=0 .{ }^{1}$ The transportation of residual oil from the refinery to demand center I results in the final material balance equation:

$$
\mathrm{x}_{6}-\mathrm{x}_{8}=0 .
$$

Two more constraints must be added to ensure that the demands for coal and residual oil are met. Assurne the demand for coal at demand center $H$ is $Q_{1}$ and the demand for residual oil at demand center $\mathrm{I}$ is $Q_{2}$. Then,

$$
\begin{aligned}
& x_{7} \supseteq Q_{1} \\
& x_{8} \supseteq Q_{2} .
\end{aligned}
$$

These equations and inequalities define the linear constraint space for this energy system. In order to complete the LP, an objective function must be specified. Let $\mathrm{c}_{\mathrm{i}}$, $i=1, \ldots, 8$, be the cost associated with the material flows, $x_{i}, i=1, \ldots, 8$, respectively. For instance, let $c_{1}$ represent the unit cost of producing coal at source $A$ and let $c_{7}$ represent the unit cost of shipping coal to demand center $\mathrm{H}$. Asssuming that the total cost of energy is to be minimized, the objective function can be represented as .

$$
\min c_{1} x_{1}+\ldots+c_{8} x_{8}
$$

Formally, the example problem is:

$$
\min c_{1} x_{1}+\ldots+c_{8} x_{8}
$$

$I_{\text {In this }}$ example, it is assumed that the units of the materials are all the same. since PIES uses standard physical units, they are not the same and conversion factors are needed. 
subject to

$$
\begin{aligned}
& x_{1}+x_{2} \\
& \left.\mathrm{x}_{3} \quad \leq \mathrm{b}_{2}\right\} \text { supply constraints } \\
& x_{i}^{\prime}
\end{aligned}
$$

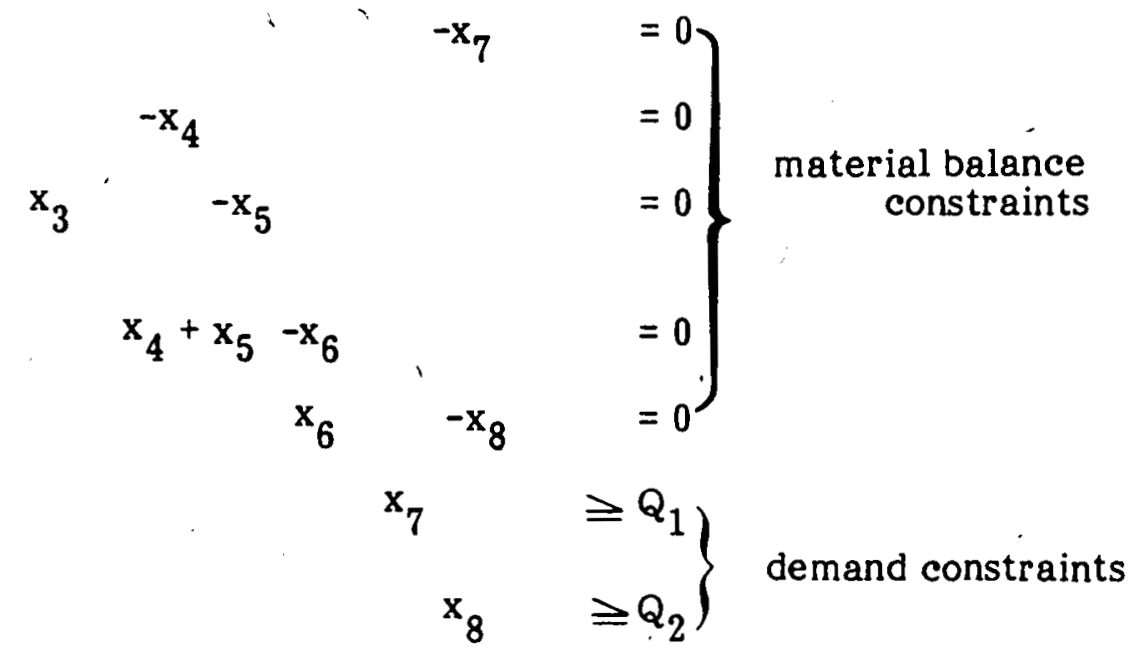

$$
\begin{aligned}
& x_{i} \geqslant 0 \quad i=1, \ldots, 8
\end{aligned}
$$

In this example, the second set of constraints, process limit equations, have not been considered. These equations restrict the capacity of facilities. If the capacity of the refinery, denoted in the example by $F$, were limited to $b_{3}$ units of capacity, then the following process limit equation would be inclúded in the constraints:

$$
\mathrm{x}_{4}+\mathrm{x}_{5} \leq \mathrm{b}_{3} .
$$

In general terms, the LP is represented mathematically in the following form:

$$
\min c_{1} x_{1}+c_{2} x_{2}+\ldots+c_{s} x_{s}
$$

subject to

$$
\begin{gathered}
a_{11} x_{1}+a_{12} x_{2}+\ldots+a_{1 s} x_{s} \leq b_{1} \\
\cdot \\
\cdot \\
a_{r 1} x_{1}+a_{r 2} x_{2}+\ldots+a_{r s} x_{s} \leq b_{r} \\
x_{1} \geq 0, \ldots, x_{s} \geq 0
\end{gathered}
$$


where $r \leq s$ and $c_{1}, \ldots, c_{s} i a_{11}, \ldots, a_{1 s}, \ldots, a_{r l}, \ldots a_{r s} ;$

and $b_{1}, \ldots, b_{r}$ are inputs and $x_{1}, \ldots, x_{s}$ are unknowns. Alternatively, this formulation can be expressed in matrix notation as:

$$
\min \mathrm{e}^{\mathrm{T}} \mathrm{X}
$$

subject to

$$
\begin{aligned}
& A x \leq b \\
& x \geqslant 0
\end{aligned}
$$

where $c$ and $X$ are both s-dimensional vecturs, $b$ is an $r$-dimcneional vector, $A$ is an r x s matrix, $s$ is the number of energy activities modeled, and $r$ is the number of constraints. Again, $\mathrm{X}$ is an unknown, and $\mathrm{c}, \mathrm{b}$, and $\overline{\mathrm{A}}$ are inputs.

The supply side has been formulated as an LP problem without considering the demand for energy, which is addressed in the next section.

THE DEMAND REPRESENTATION

First, we show a method for obtaining an equilibrium point in the one-product case, and then the way in which PIES has adapted this methodology into a linear program is indicated.

Figure 2 depicts typical supply and demand curves for the one-product case. In the figure, area A is consumers' surplus, the difference between what consumers would be willing to pay for a product and what they actually pay. Area-B is producers' surplus, the difference between what producers get for their products and what they would be willing to accept. A price quantity pair that maximizes the sum of consumers' and producers' surplus is an equilibrium in the one-product case.

The maximization of consumers' and producers' surplus is equivalent to maximization of the difference between the areas beneath the supply and demand curves.

Suppose it is desired to solve for an equilibrium by maximization of the sum of consumers' and producers' surplus. In most cases such as that depicted in Figure 2, the 


\section{FIGURE - 2 \\ CONSUMERS' AND PRODUCERS' SURPLUS}

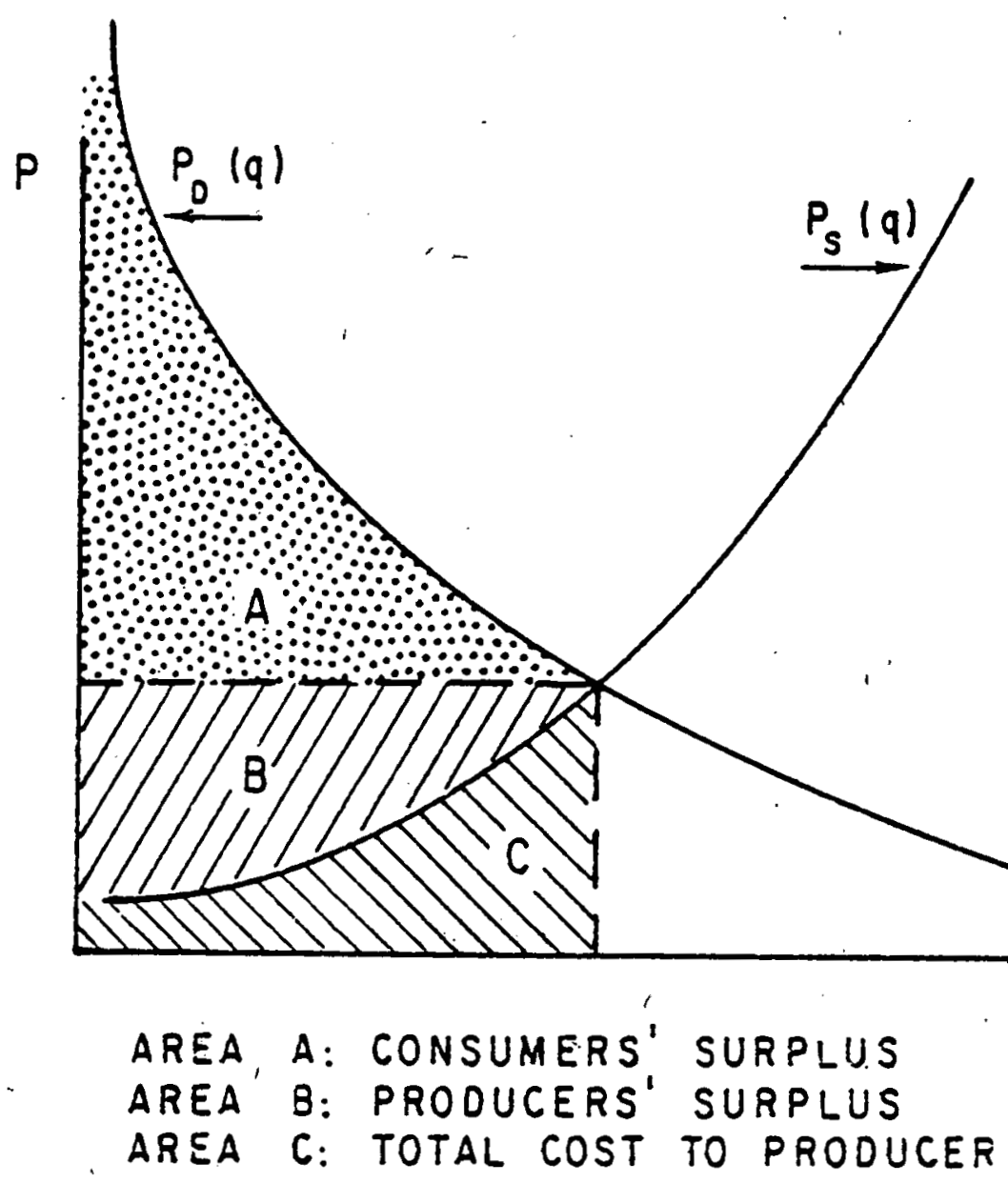

objective function is non-linear. To use LP techniques, these curves are approximated by step functions. PIES supply curves are input directly as step functions; the demand curves are approximated in the PIES Integrating Model.

The PIES Demand Model using historical data, forecasts for each region, quantities, prices, and elasticities of demand (both own and cross) assumed to exist in the target year. For the one variable demand function of Figure 2, let $Q$ denote quantity, $P$ denote price, and $\epsilon$ denote elasticity of demand. If elasticity is constant,

$$
\frac{\Delta Q}{Q}=\epsilon \frac{\Delta P}{P}
$$


In its differential equation form, we obtain:

$$
\frac{d Q}{Q}=\epsilon \frac{d P}{P} .
$$

Integrating, we get

$$
\ln Q=\ln P+k
$$

where $\mathrm{k}$ denotes the constant of integration which is evaluated using the initial quantity, $Q_{0}$, and price $P_{0}$ obtained from the Demand Model

$$
\ln Q_{0}=\epsilon \ln P_{0}+k .
$$

Substituting from equation (2) into (1) gives

$$
Q=\exp (k+\epsilon \ln P)
$$

where $k=\ln Q_{0}-\epsilon \ln P_{0^{\circ}}$

This continuous curve is approximated by a step function in the following manner. First, obtain new prices, which are 1\%, 5\%, 15\%, 35\%, and $75 \%$ above and below the initial demand model price, $\mathrm{P}_{0}$. Denote the five prices below $\mathrm{P}_{0}$ as $\mathrm{P}_{1}$ through $\mathrm{P}_{5}$ and the five prices above $P_{0}$ as $P_{-1}$ through $P_{-5}$. These values substitute for $P$ in equation (1) to obtain the quantity associated with each price. These quantities determine the length of each step on the demand curve. Figure 3 depicts a demand approximation formed in this manner.

The area beneath the demand curve is found by calculating the area of the rectangles formed by multiplying the length of each step by the corresponding price. Let $Y_{i}$ be a variable indicating a quantity between zero and the length of the step in the demand curve as depicted in Figure 3. The area beneath the demand curve is

$$
\sum_{i} P_{i} Y_{i}
$$

where $i$ is between -5 and 5 , and $Y_{0}=0$.

The next step is integrating the demand approximation with the supply side of the energy system. 


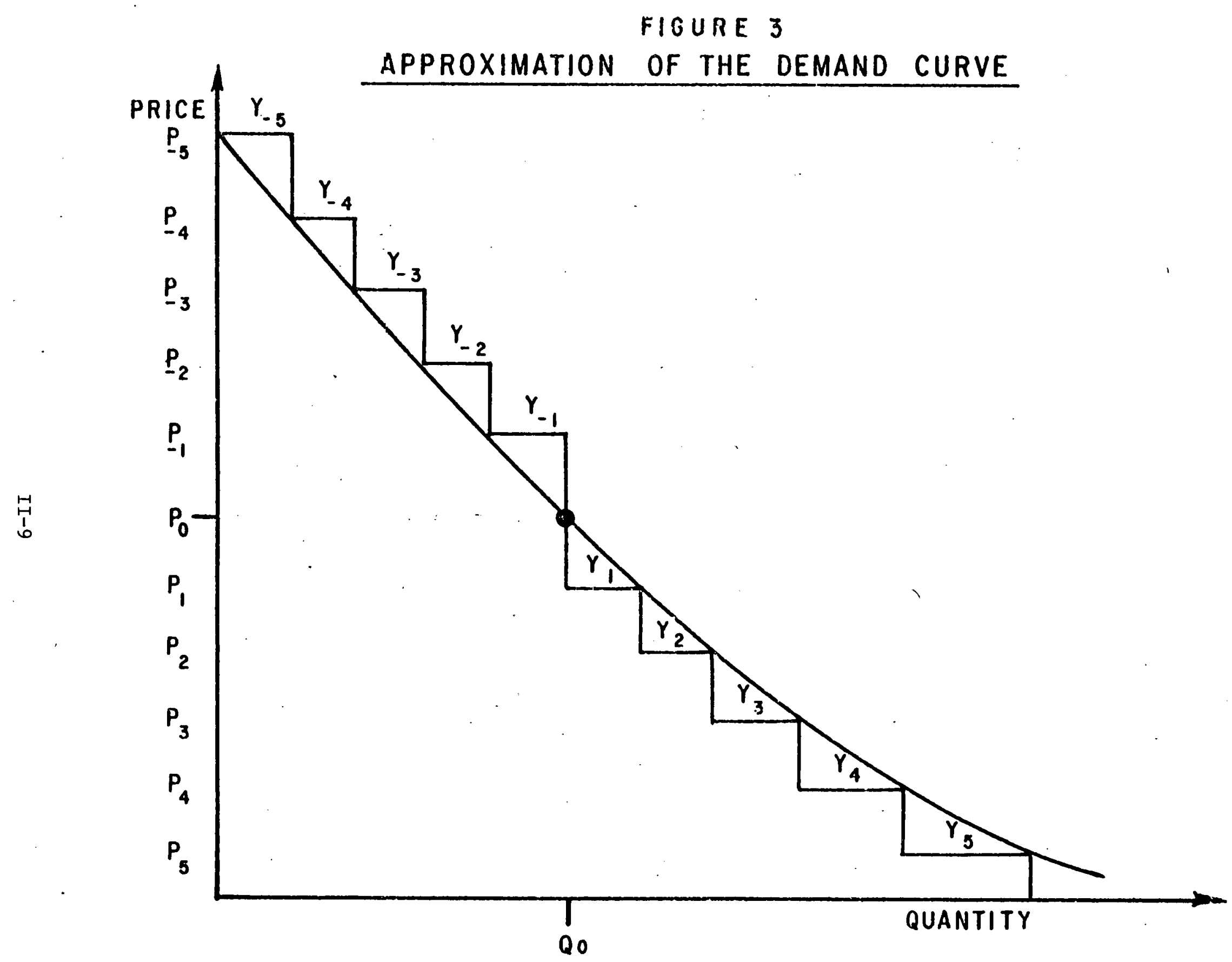


This subsection describes the PIES algorithm. Chapter II of volume IV provides a more complete discussion of the algorithm. The more theoretical aspects of this algorithm are contained in the appendix of volume IV.

- Under the assumptions that we are solving an LP whose objective function is the maximization of the sum of consumers' and producers' surplus, for the one-dimensional case, we maximize the area between the demand and supply curves. Since the area under the supply curve is equal to the total cost to the supplier under PIES economic assumptions the objective function is

$$
\max \quad \sum_{i} P_{i} Y_{i}-c^{T} x .
$$

The constraints of the LP' $a r e$ the process limit equations and the material balance equations indicated above, represented by $A_{1} X \leq b$. In addition, an equation of the form $A_{2} X=Q$ requires that supply activities, $A_{2} X$, meet the demands specified by the vector $\dot{Q}$.

Since the solution of the LP determines the intersection of the supply and demand step functions, this solution serves as a potential equilibrium. However, it may not be an equilibrium because of two considerations.

One, since the demand curve, a continuous curve produced from quantity, price, and elasticity estimates from the Demand Model, is represented in the LP by a step function approximation, the solution of the LP may not be on the continuous demand curve. Two, the LP formulation does not provide for inter-fuel effects. That is, the LP described above assumes that the cross-elasticities of demand are zero and, hence, that consumers will not substitute fuels for one another based on price.

To handle these problems, PIES solves several LPs in turn. Each LP is modified to incorporate a new demand approximation and new demand estimates based on the previous PIES solution. This procedure is repeated until prespecified convergence criteria are met. 
The convergence criteria require the difference between the price and associated qunntity obtained from two successive solutions of the $L \dot{P}$ to be within an acceptable tolerance.

Figure 4, which is described in more detail in Volume IV, depicts the movement of the 1.P. An cxample of the formulation of an encrgy problen is given in the next sectiml.

\section{FIGURE 4 \\ APPROXIMATION OF SUPPLY ANU DEMANO CURVES}

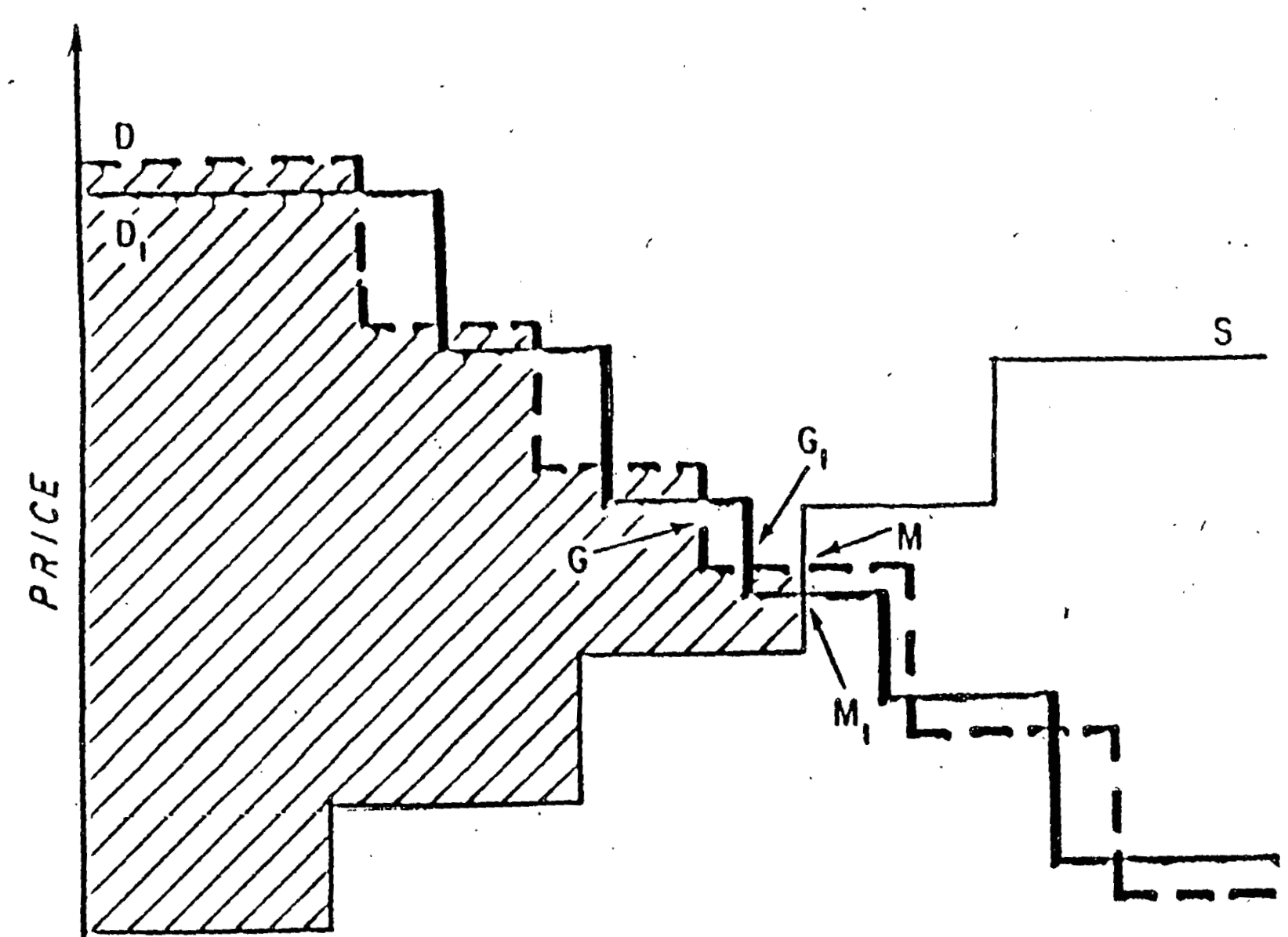

\section{QUANTITY}




\section{SAMPLE PIES LP PROBLEM}

This example of an energy system in the PIES environment is taken from the FEA Project Independence Report, November 1974. The problem is expressed in terms of a linear program as described in section II.

The example is simple and selective; a full example of PIES would be too complicated for illustrative purposes. A typical PIES solution contains the quantities and prices of each fuel that determine the equilibrium price for each region. Further, taxation and regulation of fuels, which are omitted here, are normally included in the PIES environment.

The problem involves two forms of primary energy, coal and oil. Coal is mined and shipped directly to demand regions. For simplicity, two production and two demand regions for coal are used. Oil, however, is pumped and transported to refineries to be converted to light and heavy oils, and then is transported to demand regions. Two oil regions and two refinery centers are used. A diagram of this energy network appears in Figure 5.

The production levels for coal for the sample problem are contained in Table 1.

TABLE 1. PRODUCTION LEVELS AND

RESOURCE REQUTREMENTS FOR COAL

\begin{tabular}{lccc} 
& $\begin{array}{c}\text { Production } \\
\text { (Ton/Day) }\end{array}$ & $\begin{array}{c}\text { Minimum } \\
\text { Price/Ton }\end{array}$ & $\begin{array}{c}\text { New } \\
\text { Capital/Ton }\end{array}$ \\
\cline { 2 - 4 } COAL & $0-300$ & $\$ 5$ & $\begin{array}{r}\$ 1 \\
6\end{array}$ \\
REGION 1 & $300-600$ & 6 & 5 \\
& $600-1,000$ & 8 & 10 \\
\hline & & & \\
COAL & $0-200$ & 4 & 1 \\
REGION 2 & $500-1,100$ & 5 & 5 \\
\end{tabular}


FIGURE 5

\section{SAMPLE ENERGY SYSTEM NETWORK}

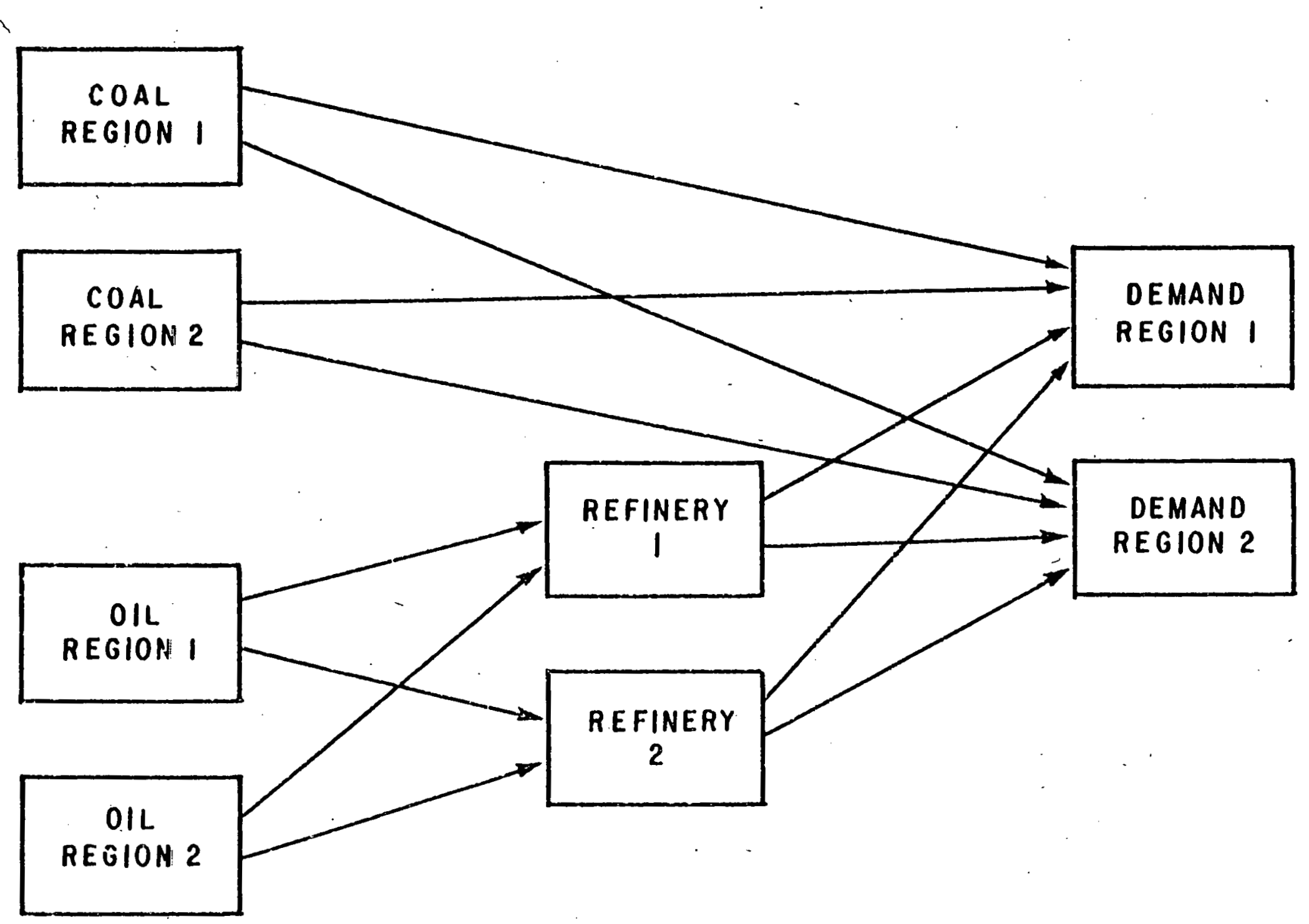


The coal mined in both regions is of uniform quality. Within each region, three levels of production are specified, identifying three points on the supply curves for price, new capital, and steel.

Coal transportation costs from mine to demand region are shown in Table 2.

TABLE 2. COAL TRANSPORT COSTS

(Dollars/Ton) ,

\begin{tabular}{|c|c|c|}
\hline . & $\begin{array}{l}\text { Demand } \\
\text { Region } 1 \\
\end{array}$ & $\begin{array}{l}\text { Demand } \\
\text { Region } 2 \\
\end{array}$ \\
\hline Coal Region 1 & $\$ 1.00$ & $\$ 2.50$ \\
\hline Coal Region 2 & .75 & 2.75 \\
\hline
\end{tabular}

As with coal, the supply curve for oil is approximated by a step function for each oil region. The price and the resource requirements for each of 2 oil production levels are contained in Table 3. Oil transportation costs from oil regions to refinery centers, are given in Table 4.

TABLE 3. PRODUCTION LEVEL AND RESOURCE REQUIREIMENTS FOR OIL

\begin{tabular}{|c|c|c|c|}
\hline & $\begin{array}{c}\text { Production Level } \\
\text { (MB/D })^{*}\end{array}$ & $\begin{array}{l}\text { Minimum } \\
\text { Price/B }\end{array}$ & New Capital/MB \\
\hline $\begin{array}{l}\text { OIL } \\
\text { REGION } 1\end{array}$ & $\begin{array}{r}0-1,100 \\
1,100-2,300\end{array}$ & $\begin{array}{rl}\$ & 1.00 \\
& 1.50\end{array}$ & $\begin{array}{r}0 \\
10\end{array}$ \\
\hline $\begin{array}{l}\text { OIL } \\
\text { REGION } 2\end{array}$ & $\begin{array}{r}0-1,300 \\
1,300-2,400\end{array}$ & $\begin{array}{l}1.25 \\
1.50\end{array}$ & $\begin{array}{r}0 \\
15\end{array}$ \\
\hline
\end{tabular}


TABLE 4. OIL TRANSPORT COSTS TO REFINERY CENTERS

(Dollars/Barrel)

$\begin{array}{cccc} & \begin{array}{c}\text { Refinery } \\ \text { Center 1 }\end{array} & & \begin{array}{c}\text { Refinery } \\ \text { Center 2 }\end{array} \\ \text { Oil Region 1 } & \$ 2.00 & & \$ 3.00 \\ \text { Oil Region 2 } & 4.00 & & 2.00\end{array}$

Refineries differ in terms of yield for each product (yield patterns). Table 5 contains the yield patterns and costs for refineries 1 and 2.

TABLE 5. REFINERY YIELDS AND COSTS

$\begin{array}{lrrr} & \text { Refinery } 1 & & \text { Refinery 2 } \\ \text { Light Oil } & .60 & & .50 \\ \text { Heavy Oil } & .40 & .50 \\ \text { Cost/Barrel } & \$ 6.50 & & \$ 5.00\end{array}$

The transportation costs of refined products from refinery to demand regions are given in Table 6.

TABLE 6. OIL TRANSPORT COSTS TO DEMAND REGIONS (Dollars/Barrel)

$\begin{array}{cccc} & \begin{array}{c}\text { Demand } \\ \text { Center 1 }\end{array} & & \begin{array}{c}\text { Demand } \\ \text { Center 2 }\end{array} \\ \text { Refinery 1 } & \$ 1.00 & & \$ 1.20 \\ \text { Refinery 2 } & 1.00 & 1.50\end{array}$


Given the data for the sample problem, the supply side can be formulated mathematically. The variables are as follows:

$C_{i, j} \quad$ Coal in region $i$ at increment $j$

$\mathrm{O}_{i, j} \quad$ Oil in region $i$ at increment $j$

$\mathrm{CT}_{\mathrm{i}, \mathrm{k}} \quad$ Coal transported from region $\mathrm{i}$ to region $\mathrm{k}$

$\mathrm{OT}_{\mathrm{i}, \mathrm{k}} \quad$ Oil transported from region $\mathrm{i}$ to region $\mathrm{k}$

$R_{i} \quad$ Level of operation of refinery $i$

$\mathrm{L}_{\mathrm{i}, \mathrm{k}} \quad$ Light oil transported from region $\mathrm{i}$ to region $\mathrm{k}$

$\mathrm{H}_{i, k} \quad$ Heavy oil transported from region $\mathrm{i}$ to region $\mathrm{k}$

$\mathrm{DL}_{\mathrm{k}} \quad$ Demand for light oil in region $\mathrm{k}$

$\mathrm{DH}_{\mathrm{k}} \quad$ Demand for heavy oil in region $\mathrm{k}$

$\mathrm{DC}_{\mathrm{k}} \quad$ Demand for coal in region $\mathrm{k}$

$\mathrm{PL}_{\mathrm{k}} \quad$ Price of light oil in region $\mathrm{k}$

$\mathrm{PH}_{\mathrm{k}} \quad$ Price of heavy oil in region $\mathrm{k}$

$\mathrm{PC}_{\mathrm{k}} \quad$ Price of coal in region $\mathrm{k}$

Using these variables and Tables 1 through 6,21 sets of equations and inequalities representing the supply of coal and oil to meet demands for light oil, heavy oil, and coal, are obtained, as follows:

1. Coal Production Limits, Region 1

$$
\begin{aligned}
& 0 \leq \mathrm{C}_{1,1} \leq 300 \\
& 0 \leq \mathrm{C}_{1,2} \leq 300 \\
& 0 \leq \mathrm{C}_{1,3} \leq 400
\end{aligned}
$$

2. Coal Production Limits, Region 2

$$
\begin{aligned}
& 0 \leq \mathrm{c}_{2,1} \leq 200 \\
& 0 \leq \mathrm{C}_{2,2} \leq 300 \\
& 0 \leq \mathrm{C}_{2,3} \leq 600
\end{aligned}
$$


3. Oil Production Limits, Region 1

$0 \leq o_{1,1} \leq 1,100$
$0 \leq o_{1,2} \leq 1,200$

4. Oil Production Limits, Region 2

$0 \leq \mathrm{o}_{2,1} \leq 1,300$

$0 \leq \mathrm{O}_{2,2} \leq 1,100$

5. Mass Balance, Coal Region 1

$\sum_{j=1}^{3} \mathrm{C}_{1, j}-\sum_{\mathrm{k}=1}^{2} \mathrm{CT}_{1, \mathrm{k}}=0$

6. Mass Balance, Coal Region 2

$\sum_{j=1}^{3} C_{2, j}-\sum_{k=1}^{2} C T_{2, k}=0$

7. Mass Balance, Oil Region 1

$\sum_{j=1}^{2} O_{1, j}-\sum_{k=1}^{2} O_{1, k}=0$

8. Mass Balance, Oil Region 2

$\sum_{j=1}^{2} O_{2, j}-\sum_{k=1}^{2} O_{2, k}=0$

9. Crude Mass Balance, Refinery Region 1

$\sum_{i=1}^{2} \mathrm{OT}_{\mathrm{i}, 1}-\mathrm{R}_{1}=0$

10. Crude Mass Balance, Refinery Region 2

$\sum_{i=1}^{2} \mathrm{OT}_{\mathrm{i}, 2}-\mathrm{R}_{2}=0$

11. Light Oil Mass Balance, Refinery Region $1^{\prime}$

$\sum_{k=1}^{2}-L_{1, k}-.6 R_{1} \cdot 0$.

12. Light Oil Mass Bálance, Refinery Region 2

$\sum_{k=1}^{2} L_{2, k}-.5 R_{2}=0$ 
13. Heavy Oil Mass Balance, Refinery Region 1

2

$\sum_{k=1} H_{1, k}-.4 R_{1}=0$

14. Heavy Oil Mass Balance, Refinery Region 2

$\sum_{k=1}^{2} H_{2 ; k}-.5 R_{2}=0$

15. Coal Demand Balance, Region 1

$$
\sum_{i=1}^{2} \mathrm{Cr}_{\mathrm{i}, 1}=\mathrm{DC}_{1}
$$

16. Coal Demand Balance, Region 2

$$
\sum_{i=1}^{2} \mathrm{CT}_{\mathrm{i}, 2}=\mathrm{DC}_{2}
$$

17. Light Oil Demand Balance, Region 1

$$
\sum_{i=1}^{2} L_{i, 1}=D_{1}
$$

18. Light Oil Demand Balance, Region 2

$$
\sum_{\mathrm{i}=1}^{2} \mathrm{~L}_{\mathrm{i}, 2}=\mathrm{DL}_{2}
$$

19. Heavy Oil Demand Balance, Region 1

$$
\sum_{\mathrm{i}=1}^{2} \mathrm{H}_{\mathrm{i}, 1}=\mathrm{DH}_{1}
$$

20. Heavy Oil Demand Balance, Region 2

$$
\sum_{\mathrm{i}=1}^{2} \mathrm{H}_{\mathrm{i}, 2}=\mathrm{DH}_{2}
$$

21. Supply Price Function

$$
\begin{aligned}
& 5.00 \mathrm{C}_{1,1}+6.00 \mathrm{C}_{1,2}+8.00 \mathrm{C}_{1,3}+4.00 \mathrm{C}_{2,1} \\
& +5.00 \mathrm{C}_{2,2}+7.00 \mathrm{C}_{2,3}+1.00 \mathrm{O}_{1,1}+1.50 \mathrm{O}_{1,2} \\
& +1.25 \mathrm{O}_{2,1}+1.50 \mathrm{O}_{2,2}+1.00 \mathrm{CT}_{1,1}+2.50 \mathrm{CT}_{1,2} \\
& +.75 \mathrm{CT}_{2,1}+2.75 \mathrm{CT}_{2,2}+2.00 \mathrm{OT}_{1,1}+3.00 \mathrm{OT}_{1,2} \\
& +4.00 \mathrm{OT}_{2,1}+2.00 \mathrm{OT}_{2,2}+6.50 \mathrm{R}_{1}+5.00 \mathrm{R}_{2}
\end{aligned}
$$




$$
\begin{aligned}
& +1.00 \mathrm{~L}_{1,1}+1.20 \mathrm{~L}_{1,2}+1.00 \mathrm{~L}_{2,1}+1.50 \mathrm{~L}_{2,2} \\
& +1.00 \mathrm{H}_{1,1}+1.20 \mathrm{H}_{1,2}+1.00 \mathrm{H}_{2,1}+1.50 \mathrm{H}_{2,2}
\end{aligned}
$$

Several points need to be made about these mathematical representations. Equation 21 represents the supply part of the objective function being minimized; the variables representing the demand approximation are not included. The production limits for coal and oil, in equations 1 through 4 , are the amount of coal and oil produced at the appropriate step of the step function. Thus, although the second step of the supply function approximation for coal in coal region $\mathrm{C} 1$ is the production of 300 to 600 tons of coal per day, the amount of coal that could be produced for $\$ 6$ in coal region $\mathrm{C} 1$ is up to 300 tons per day. Finally, the mass balance or material balance equations force the amount of fuel leaving a location to equal the amount of fuel entering that location, net of consumption and losses.

The demand balance equations reflect the fact that the demand for coal, light oil, and heavy oil must be met in each demand region. Equations 15-20 do not include the demand approximation variables. The variables $\mathrm{DH}_{\mathrm{k}}, \mathrm{DL}_{\mathrm{k}}$, and $\mathrm{DC}_{\mathrm{k}}, \mathrm{k}=1,2$, initially are supplied by the demand model and are recalculated using the demand function after each iteration of the equilibrating mechanism, that is, after each LP solution. For this example, the initial estimates of demands and prices for each of the two regions are: $1,200 \mathrm{MB} / \mathrm{D}$ of light oil at a price of $\$ 16 / \mathrm{B}, 1,000 \mathrm{MB} / \mathrm{D}$ of heavy oil at a price of $\$ 12 / \mathrm{B}$, and 1,000 tons/D of coal at $\$ 12 /$ ton.

Since these demands are assumed to be price-sensitive, the elasticities of demand for these products are required in order to calculate the demand function. Table 7 contains the elasticities for this example. 
TABLE 7. ELASTICITIES

\begin{tabular}{|c|c|c|c|}
\hline & Light Oil & Heavy Oil & Coa \\
\hline Light Oil & -.5 & .2 & .1 \\
\hline Heavy Oil & .1 & -.5 & \\
\hline Coal & .1 & .2 & -.75 \\
\hline
\end{tabular}

The LP determines supply prices based on satisfying the demand associated with constraints 15-20. If the system is in equilibrium, the supply price will equal the demand price. If not, new demand prices are determined; the demands associated with these prices and consistent with the elasticities are calculated; and a new LP problem is solved to determine new supply prices. This process is continued until an approximate equilibrium solution is obtained (that is, supply equals demand within a specified tolerance limit). This example was solved in this manner. Table 8 , contains the results, with and. without the resource constraints expressed in equations 19 and 20. The next subsections discuss both solutions.

Market Equilibrium Without Constraints

Table 9 summarizes the final prices and quantities for light oil, heavy oil, and coal. The initial estimates of the equilibrium prices and demands - $\$ 16$ and 1,200 $\mathrm{NB} / \mathrm{D}$ for light oil, $\$ 12$ and 1,000 MB/D for heavy oil, and $\$ 12$ and 1,000 tons/D for coal - have been changed by the model:

A few observations can be made from the solution without constraints. Table 1 indicated that total coal production in both coal regions $\mathrm{C} 1$ and $\mathrm{C} 2$ could not exceed 2,100 tons/D. The final solution shows the demand in demand regions $D 1$ and $D 2$ as exactly 2,100 tons/D, the entire production capacity of coal. However, the entire oil production capacity is $4,700 \mathrm{MB} / \mathrm{D}$ (Table 3 ) and the total demand, including both light and heavy oil, is $4,614 \mathrm{MD} / \mathrm{D}$. Thus, $86 \mathrm{MD} / \mathrm{D}$ of potential oil remain untapped. From Table 8 (variable $O_{1,2}$ ), observe that the untapped oil was from the second increment in oil 
region 01 , or the most expensive oil in that region. The total demand for each product exceeded the initial estimates and that the final prices were lower than the initial estimates.

Table 8 shows that refineries 1 and 2 handled $2,110 \mathrm{MB} / \mathrm{D}$ and $2,504 \mathrm{MB} / \mathrm{D}$, respectively. The higher volume of oil handled by refinery 2 was due to the $\$ 1.50$ cost differential and the different yield patterns of the refineries (Table 5).

This example illustrates the regional differences and price adjustments which can occur without resource constraints. If resource constraints are introduced, the same procedure can be used, as explained in the following subsection. 
TABLE 8. EQUILIBRIUM ENERGY BALANCES

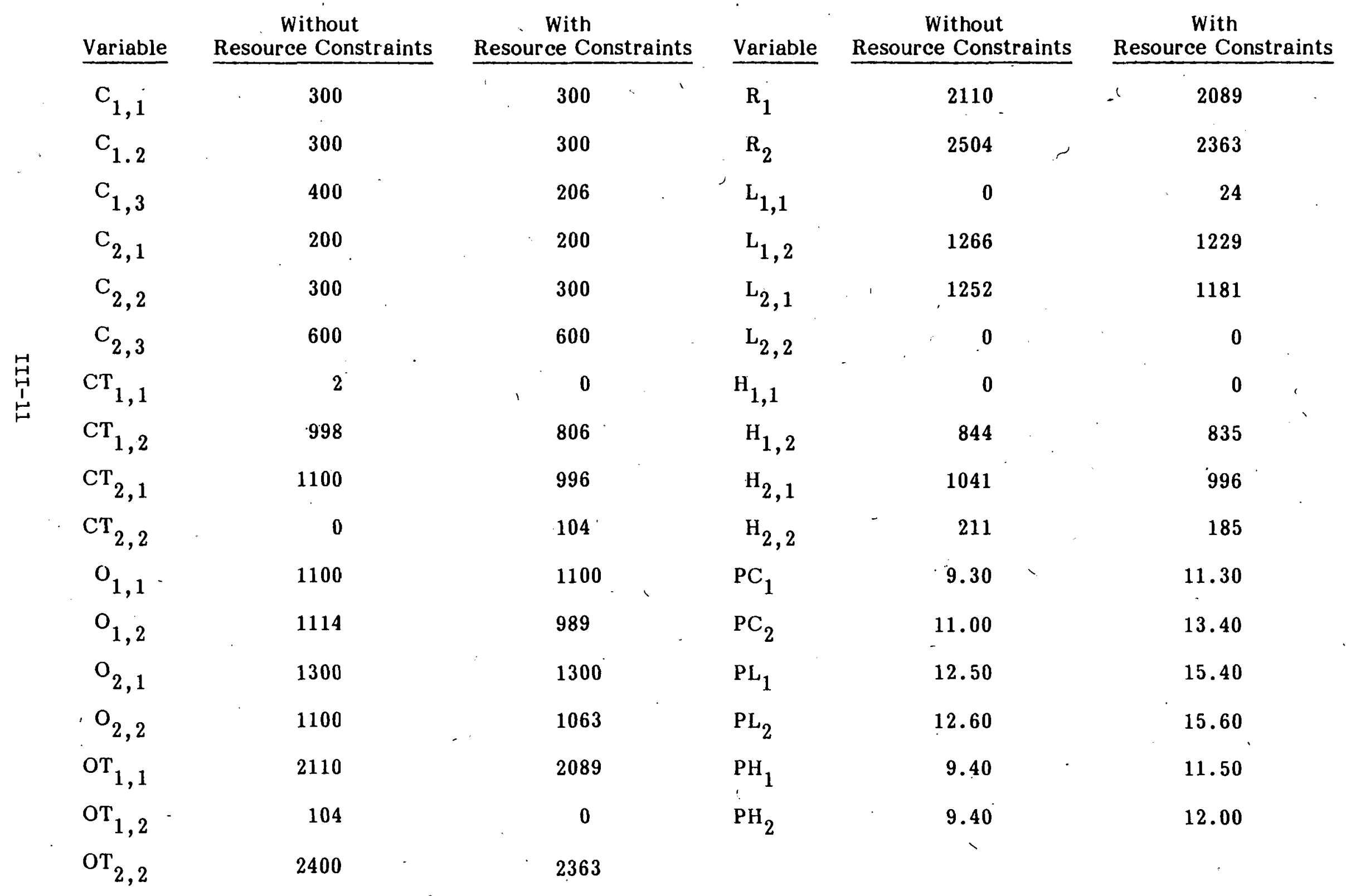


TABLE 9. PRICE AND QUANTITY SUMMARY

(Without Constraints),

Light Oil Heavy Oil Cool

\begin{tabular}{|c|c|}
\hline \multicolumn{2}{|c|}{ Price } \\
\hline $\begin{array}{l}\text { Demand } \\
\text { Region } 1\end{array}$ & $\begin{array}{l}\text { Demand } \\
\text { Region } 2\end{array}$ \\
\hline$\$ 12.5$ & $\$ 12.6$ \\
\hline 9.4 & $\begin{array}{r}9.4 \\
11.0\end{array}$ \\
\hline
\end{tabular}

\begin{tabular}{|c|c|}
\hline \multicolumn{2}{|c|}{ Quantity } \\
\hline $\begin{array}{l}\text { Demand } \\
\text { Region } 1 \\
\end{array}$ & $\begin{array}{l}\text { Demand } \\
\text { Region } 2 \\
\end{array}$ \\
\hline & 1,266 \\
\hline 1,041 & 1,055 \\
\hline 1,102 & 998 \\
\hline
\end{tabular}


U.S. DEPARTMENT OF ENERGY

ENERGY INFORMATION ADMINISTRATION OFFICE OF ENERGY INFORMATION SERVICES 1726 M ST. N.W.

WASHINGTON, D.C. 20461

OFFICIAL BUSINESS

PENALTY FOR PRIVATE USE, $\$ 300$
POSTAGE AND FEES PAID

UNITED STATES DEPARTMENT OF ENERGY DOE-350 